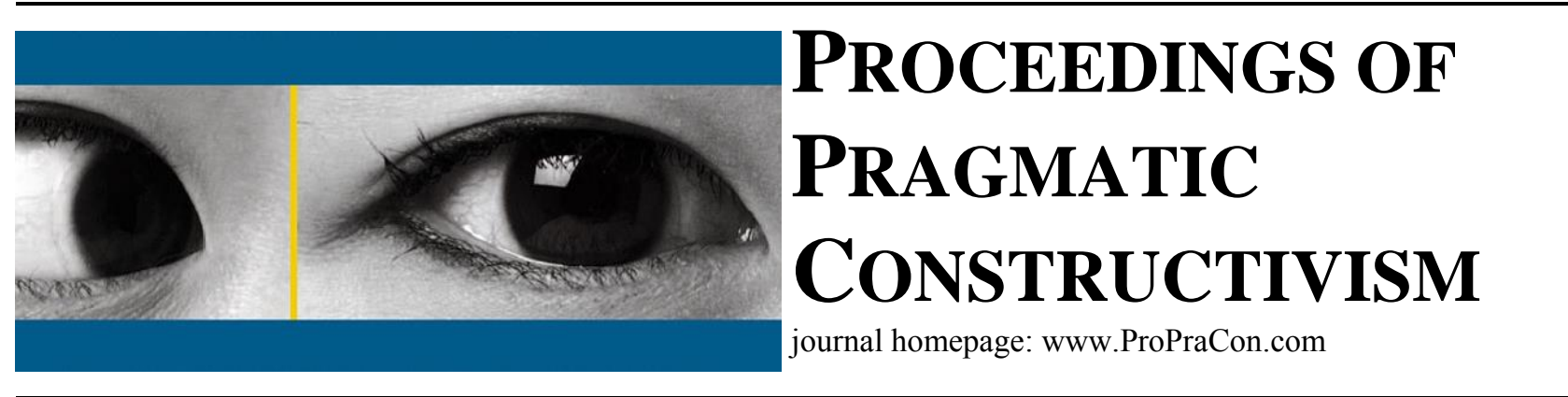

\title{
Examining technical and behavioural possibilities in developing fleet services in the machinery manufacturing context
}

\author{
Tuomas Korhonen \\ Postdoctoral Researcher \\ Cost Management Center, Laboratory of Industrial and Information Management, Tampere University of Technology, \\ Korkeakoulunkatu 10, 33720 Tampere, Finland; tuomas.korhonen@tut.fi.

\begin{abstract}
Kati Stormi
Doctoral Student

Cost Management Center, Laboratory of Industrial and Information Management, Tampere University of Technology, Korkeakoulunkatu 10, 33720 Tampere, Finland; kati.stormi@tut.fi
\end{abstract} \\ Teemu Laine \\ Assistant Professor \\ Cost Management Center, Laboratory of Industrial and Information Management, Tampere University of Technology, \\ Korkeakoulunkatu 10, 33720 Tampere, Finland; teemu.j.laine@tut.fi
}

\section{Angela Liew \\ Lecturer}

Accounting and Finance, Faculty of Business and Economics, The University of Auckland, New Zealand Private Bag 92019, Auckland 1142, New Zealand; a.liew@auckland.ac.nz

\begin{abstract}
This paper shows how service development for a machinery fleet can be supported by financial analyses. In particular, the paper shows how service managers' work can be supported by accounting information. The paper draws upon an interventionist case study at a machinery manufacturer in Finland. The paper contributes to the literature on pragmatic constructivism by extending its usability into new groups of managerial actors in the timely context of service development for machinery fleets. Moreover, the paper contributes to the servitization literature, by showing ways to identify technical and behavioural possibilities and to overcome related difficulties in manufacturing companies' transition to service business.
\end{abstract}

\section{Acknowledgements}

The research project resulting in this paper has been funded by the Centre for Technology and Innovation in Finland (TEKES) via DIMECC: S4FLEET research program. The authors wish to thank the managers of the case company for the access to the fruitful dataset.

Keywords: Service development; machinery fleet; financial analyses. 


\section{Introduction}

Prior research has documented the need to find support from accounting information in actual managerial work (e.g., Hall, 2010; Jakobsen et al. 2011). This paper especially focuses on how managers in machinery manufacturing companies can benefit from management accounting information in their endeavours to gain new business from services. The transition from manufacturing to (increased) service business is often called servitization (Laine et al., 2012a; Lindholm et al., 2017). In this paper, new service business is developed linked to a "machinery fleet". A machinery fleet is the installed base of a company's own delivered machines (in use at the customers); a machine manufacturer can offer their services, such as maintenance, spare parts, training or optimization linked this fleet (Laine, 2009).

The aim of the paper is to gain understanding about the types of management accounting information managers find support in fleet service business development, to unveil technical and behavioural possibilities in developing fleet services in the machinery manufacturing context. The paper takes advantage of (1) pragmatic constructivist thoughts on an (managerial) actor at the centre of the analysis and (2) accounting information in new product and service development. Therefore, first, the paper acknowledges that actors collaboratively and communicatively construct accounting facts and estimate the future profitability of products and services under development (Laine et al., 2016a; Laine et al., 2016b). These accounting facts and estimates are situated in the context of actors' present possibilities and values (Nørreklit et al., 2010; Jakobsen et al., 2011; Nørreklit et al., 2016). Second, the paper also acknowledges that in developing products and services, actors can benefit from enabling management accounting and control systems (Ahrens and Chapman 2004; Davila et al. 2009). However, there is still too little understanding about what types of accounting information (could) support managers in the fleet service development context.

The empirical findings of the paper are based on an interventionist case study (Jönsson and Lukka, 2006; Suomala et al., 2014; Lukka and Suomala, 2014) of a globally operating machinery manufacturer. The contribution of the paper is based on unveiling the business logic change process of machinery manufacturers aiming at extended service business (cf. Oliva and Kallenberg, 2003, Laine 2009). More particularly, the paper describes a process of defining and structuring the technical possibilities stemming from servitization (see e.g., Lindholm et al., 2017), and provides insights into discussions about the behavioural possibilities, i.e. building a shared understanding about servitization within a company (Laine et al., 2012a; 2012b) - and choosing most promising avenues for development efforts accordingly. Methodologically, the paper extends the usage of pragmatic constructivism to service business development, within the timely servitization phenomenon.

\section{Literature review}

\subsection{Accounting information systems in product and service development}

To lay ground for our study in new service development, we draw upon current knowledge on quite a similar context, namely the context of new product development (NPD). NPD productivity can be improved through an efficient and effective process (Cooper and Edgett, 2008) that is enhanced by means of automation and process technology (Microsoft, 2005). Information technology is increasingly being developed and used by firms to better manage and coordinate their NPD process (Barczak et al., 2007). Senior management often employ it to alert them of the potential issues behind the innovations (Krishnan and Ulrich, 2001). The failures of many new products are closely linked to the weaknesses of the NPD process (Cooper and Kleinschmidt, 1996; Stewart-Knox and Michell, 2003) including inadequate focus on the financial impacts of a product (cf. Laine et al., 2016a). Effective use of the process is thus a key factor behind the performance of an organisation's new products (Anderson, 2008), and such effective use can be achieved through process technology (Microsoft, 2005; Cooper and Edgett, 2008).

Barczak et al. (2007) was one of the seminal papers in NPD literature examining how significant information technology plays a part in NPD practices. They developed a conceptual model consisting of six specific antecedents and examined the relationships among the antecedents. Their survey study revealed that high information technology usage in NPD projects is subject to three antecedents, namely, (1) "the risk of the product being developed", (2) "the existence of a champion for specific information technologies (IT) tools", and (3) "the embeddedness of IT in the firm". However, high information technology usage is not affected by the other three antecedents, (4) "the autonomy of the [NPD] team", (5) "the innovative climate of the firm", and (6) "the sophistication of IT infrastructure and the extent in which it supports distribution of IT tools". They found similar results reported in the information technology literature from adopting information technology for NPD purposes (Teo and Choo, 2001). Their findings on "the existence of a champion for specific IT tools" was also consistent with other studies that demonstrated the importance of a champion 
when implementing any organisational information technology (Beath, 1991; Grover, 1993), or when adopting new packaging technology for producing radical or semi-radical new products (Ettlie, Bridges and O'Keefe, 1984).

Although information technology is being used more and more for managing and coordinating the work activities and NPD processes and the significance information technology plays in NPD (Barczak et al., 2007), little is known about the use and effect of it in managing and coordinating NPD (Sarin, 2009; Kawakami et al., 2011). Furthermore, few studies have since appeared in the recent five years after Kawakami et al. (2011) study. The lack of interests may be due to businesses merely adopting simple, easy-to-use ubiquitous information technology tools to help them manage and coordinate NPD (Barczak and Sultan, 2006). Businesses are still unwilling to adopt sophisticated information technology to help them (Adams-Bigelow, 2004; Barczak and Sultan, 2006) in spite of the availability of sophisticated information technology these days to help manage and coordinate NPD processes and work activities (Barczak et al., 2007). Nevertheless, one recent case study made an attempt in explaining the resulting effects on the top management group who implemented a more sophisticated information technology that came embedded with the StageGate Product Innovation Process for managing, coordinating and monitoring their NPD activities (Liew, 2015). Prior research has also reported that more informal information systems, such as accounting prototypes, may support NPD management (Laine et al., 2016b). However, more studies are still needed to better understand the impact businesses experience from adopting information technology to manage and coordinate NPD (Laine et al., 2016a). Such future studies are imperative given the current state where empirical substantiation of the resulting impact of NPD IT practices is almost non-existent (Barczak et al., 2007).

\subsection{Utilizing accounting information in the machinery fleet service context}

Service business development represents a significant change for many machinery manufacturers (Mathieu, 2001; Oliva and Kallenberg, 2003). A servitization process may involve rethinking of a machinery manufacturing company's identity, intentionally changing division of tasks between the machinery manufacturer and its customer(s) and may thus require developing new kinds of products and services and customer relationships (Laine, 2009; Laine et al., 2012b). At the same time, some scholars have reminded that the particular choices within servitization, i.e., what kinds of new products/services would be beneficial, what kinds of new customer relationships would create value to the parties involved, cannot easily be justified based on the servitization literature (Araujo and Spring, 2006; Laine, 2009), but require case-specific considerations. It is fair to say that the current and desired role of individual managerial actors has remained under-researched in the servitization context, although the managers in their different roles (e.g., service manager, spare part manager, product/service/area managers) are key to realizing the servitization process, and in attaining the desired benefits (Mathieu, 2001).

There are a few articles in the servitization literature that take into consideration the use of accounting and performance measurement information (e.g., Laine et al., 2012a; 2012b; Lindholm et al., 2017). Laine et al. (2012b) examined the need for new units of analysis at the machinery manufacturers that need to define, justify and control their servitization initiatives at different levels. Not only should accounting information help the managers to measure the financial outcomes of the new service businesses, but support the managers to identify and critically examine the emerging business possibilities. However, the promised financial benefits of the servitization have not been realized everywhere (Gebauer et al., 2005), and management accounting could play a significant role in proactively anticipating and supporting the realization of those benefits (Laine et al., 2012a; 2012b; Lindholm et al., 2017).

From the perspective of this paper, new business possibilities stemming from servitization may be both technical and behavioural in nature. Technically, the machinery manufacturing companies collect and utilize more and more information about their products in use at the customers (Oliva and Kallenberg, 2003; Laine, 2009), and this opens new opportunities for service businesses. However, the behavioural possibilities linked to this have not been thoroughly examined. Recent literature has revealed that discussions aiming at a shared understanding about servitization are needed at the machinery manufacturers (Laine et al., 2012a). Besides, the organizational structures and responsibilities need to enable the identification and realization of emerging business possibilities (Neu and Brown, 2005; Lindholm et al., 2017). What is not known, however, is the role of individual managerial actors in identifying and putting forward the possibilities, that would require new information sources and new forms of communication among the actors. This aspect underlines the usefulness of pragmatic constructivism in addressing the questions of machinery fleet service development and financial considerations therein.

\subsection{Pragmatic constructivist thoughts on the fleet service context}

Pragmatic constructivism perceives actors' reality to consist of facts, possibilities, values and communication (Nørreklit et al., 2010; Jakobsen et al., 2016; Nørreklit et al., 2016). Pragmatic constructivist thoughts have recently been used in a 
number of contexts in management accounting to understand actors' work, such as the venture capital context (Heinzelmann, 2016), financial crime (Jack, 2015), new product development (Laine et al., 2016b) and human rights (Pianezzi \& Cinquini, 2016).

In this paper, we extend the applications of pragmatic constructivism to the industrial service development context. As in any business, an actor who is responsible for developing industrial services needs to know the potential service market and potential demand to manage their services profitably. Moreover, such actor should be able to monitor the performance of service sales. The problem is, industrial services can be a fuzzy and complex entity within an organization's service offering (Laine, 2009), with dispersed sales data, localized information systems and localized service operations. Therefore, the factual possibilities to understand the service market of a manufacturing company might be scarce. In this paper, we expect that the actor finds value in profitable service operations and is able to communicate profitability information within a company if such information is first collected or constructed. In other words, we believe that service business development is driven by motivated people who actually wish to develop new, profitable business from services. To make firms benefit from these motivated service developers, we believe that these developers' managerial work needs to be supported by relevant accounting information (cf. Hall, 2010).

In all, our literature review shows that there is (1) a lack of thorough knowledge about business impacts of accounting information systems in NPD and thus likely in new service development as well, (2) a lack of a detailed understanding about technical and behavioural possibilities in developing machinery fleet services, and (3) a possible difficulty in understanding the factual possibilities in the machinery fleet service market stemming from the extended awareness of the machinery fleet in use at the customers. Hence our literature review call for deeper understanding to find support from accounting information for new service development (specifically in the machinery fleet service development context, but we expect the findings to be applicable outside this context as well).

\section{Methodology}

We use an in-depth case study at a machinery manufacturer, here called "FleetCo". FleetCo is a global manufacturer of various types of equipment used to process material. Our data set consists of twelve meetings in which FleetCo's service business development sought support from accounting calculations about actual business area sales versus theoretical service demand (see Table 1). These meetings were documented with detailed notes.

The data collected from meetings was documented as three sub case studies within FleetCo: dealer market analyses (4.1), service customer demand forecasting (4.2), and customer data analysis in fleet segmentation (4.3). By means of pragmatic constructivism, each of these sub case studies examines the types of management accounting information managers find support in service business development, in line with the aim of the paper, to unveil the technical and behavioural possibilities in developing fleet services. 
Table 1. Meetings used for data collection.

\begin{tabular}{|c|c|c|}
\hline Theme of meeting & Attendants & Date \\
\hline $\begin{array}{l}\text { Project kick-off and market area } \\
\text { analysis } 1\end{array}$ & Service development manager & $2015-02-13$ \\
\hline $\begin{array}{l}\text { Benchmarking from another } \\
\text { company }\end{array}$ & $\begin{array}{l}\text { Service development manager, Product manager, } \\
\text { Service training, Service process management, Life } \\
\text { cycle services, Information technology, } \\
\text { Maintenance operations }\end{array}$ & $2015-02-16$ \\
\hline Profitability analysis planning & Service development manager, Product manager & 2015-03-05 \\
\hline Accounting fact construction & Service development manager, Product manager & $2015-05-22$ \\
\hline Market area analysis 2 & Product manager, Market area responsible & $2015-06-12$ \\
\hline Market area analysis 2 reflection & Service development manager, Product manager & 2015-08-11 \\
\hline Planning market area analysis 3 & Service development manager & 2016-01-11 \\
\hline $\begin{array}{l}\text { Research project steering group } \\
\text { meeting }\end{array}$ & Service development manager & 2016-01-20 \\
\hline $\begin{array}{l}\text { Information sharing for new people } \\
\text { around the project }\end{array}$ & Research manager, Industrial designer & 2016-01-29 \\
\hline Market area analysis 3 & $\begin{array}{l}\text { Service development manager, Market area } \\
\text { responsible }\end{array}$ & 2016-03-08 \\
\hline Market area analysis reflection 3 & Service development manager & $2016-05-23$ \\
\hline Service demand forecasting & Service development manager, Analytics director & 2016-10-26 \\
\hline Service demand forecasting & Analytics director & 2016-11-29 \\
\hline $\begin{array}{l}\text { Service demand forecasting } \\
\text { reflection }\end{array}$ & Analytics director & 2016-11-30 \\
\hline
\end{tabular}

\section{Empirical results}

The processing that FleetCo's products do consumes wear and spare parts. Wear parts are consumed since they literally wear out as a piece of equipment processes material. Spare parts are needed to longitudinally keep the equipment up and running. In the following sections, we will go through three cases in which FleetCo tried to increase their understanding about their facts and possibilities in developing fleet services.

\subsection{Dealer market analyses}

"We increased sales five percent, but we should have increased fifteen percent." (Service development manager, 2016-01-11)

The dealer market analysis was made to understand the extent to which FleetCo's service dealers actually meet the wear and spare part demand that is linked to sold pieces of machinery. Together with the service development manager, product manager and market area responsibles, the interventionist researchers gathered the following accounting information, per dealer:

- $\quad$ the size of the machinery fleet in the area (pcs; from FleetCo's IT systems)

- the average yearly machine usage in the area (hours; estimation) 
- $\quad$ expectable wear and spare part consumption (euros; estimation)

- $\quad$ actual wear and spare part consumption (euros; from FleetCo's IT systems).

Using these pieces of information, the interventionist researchers could calculate each dealer's service market share as percentage of the actual sales from an expectable, theoretical wear and spare part consumption. Using this analysis, it could be seen that some dealers were selling fewer services than expected, meaning that some wear and/or spare part sales could have been lost to competing part manufacturers. If preferred, the organization could now communicate this information to a particular dealer or for instance start a campaign to push a low-performing dealer to acquire a higher market share in wear and spare parts.

Using the vocabulary of pragmatic constructivism, we claim that FleetCo's fleet service developers saw that the fleet size is an accounting fact. The amount of machines comprising the installed base is an integer that is formed by summing up all sold machines in an area; this integer is a fact that can be viewed from FleetCo's IT systems. The expectation is that FleetCo's service sales potential has not been fully benefited from, posing a possibility of increasing service sales via selected lower-performing dealers, in line with the value of acquiring profitable new business from services. Once communicated, there is a possibility that the service business potential could be benefited from to a higher extend than before.

\subsection{Service customer demand forecasting}

“We just want to be in the ballpark.” (Service development manager, 2016-10-26)

During the dealer analyses, interventionist researchers also entered the field of service customer demand forecasting. One of the researchers build up a statistical model that would calculate the probability of a customer to place a service order the next year, based on the customer's behaviour in ordering FleetCo's services during the past years. From FleetCo's viewpoint, it would be important to pinpoint customers that are not ordering as much as they should be, based on the size of their machinery fleet that indicates a certain theoretical consumption for both wear and spare parts.

In the vocabulary of pragmatic constructivism, a service manager knows for fact, that certain pieces of machinery have been sold in the past and certain service orders have been placed after that. There is the possibility that a customer orders services based on the size of his/her machinery fleet. On one hand, this possibility is supported by the fact that eventually a piece of machinery will break down if not properly serviced. On the other hand, a customer's machinery fleet can be partly or fully serviced by a third party, making the possibility less factual and more illusional. Again, however, the service manager is likely to adhere to company values according to which he/she is willing to increase profitable service sales. In this case it was the interventionist researcher who was able to realize the prediction model that would make the demand forecasting possibility factual. Hence, the accounting information used were:

- $\quad$ the size of the machinery fleet of a customer (pcs; from FleetCo's IT systems)

- $\quad$ the customer's previous ordering behaviour (date, euros, pcs; from FleetCo's IT systems).

Still, many possibilities to improve the model remain for FleetCo. The current prediction model could not capture the age of the machinery fleet. Understandably, the age of a piece of machinery could well correlate to its service needs, i.e. older pieces of machinery might consume different amounts of wear and spare parts than newer pieces. Neither did the model capture how the pieces of machinery are actually used at customer's sites. More detailed information about usage - whether it is easier or rougher for a piece of machinery - could make the prediction model more precise.

\subsection{Customer data analysis in fleet segmentation}

“That spreadsheet looks interesting; my fingers are itching.” (Analytics director, 2016-11-29)

Consumers and business customers are different. Demographic factors, such as age, gender and annual income on the consumer side and size, industry and location on the business side vary widely. In addition, customer buying behaviour varies. Some customers make low-cost purchases only occasionally whereas others make high-volume purchases on a regular basis. At the same time, in many companies the number of customers is large. The American multinational ecommerce company Amazon had 310 million active customer accounts as of the first quarter of $2016^{1}$. In the businessto-business B2B context, however, companies have typically only thousands of customers. If the customer base is broad, constructing an individual marketing mix for every existing customer is a tedious task. Customer segmentation is

\footnotetext{
${ }^{1}$ See: https:/www.statista.com/statistics/476196/number-of-active-amazon-customer-accounts-quarter/
} 
a way to solve this problem. Segmentation is a process of dividing customers into meaningful segments. The objective is to select the most suitable marketing strategy for every segment.

One of the interventionist researchers developed an enhanced customer segmentation model for the industrial service customers at FleetCo. The enhanced customer segmentation and properly selected marketing efforts for every segment provide a possibility to increase service sales and to increase customer satisfaction.

The customer data analysis subcase focused especially in the FleetCo's spare parts sales. In this customer data analysis, the segmentation was based on the "Recency", "Frequency" and "Monetary" value model (RFM model). RFM model divides customers into segments based on their purchase behaviour. RFM model categorizes customer purchase behaviour based on three aspects:

- The timing of a customer's most recent order (Recency, date; from FleetCo's IT systems)

- The number of a customers' orders during a time-window, for example one year (Frequency, amount; from FleetCo's IT systems)

- $\quad$ The monetary value of orders during elapsed time (Monetary value, euros; from FleetCo's IT systems).

Each RFM category was then divided into three groups of circa similarly size. For example, customers that had purchased services from FleetCo during the past six months belonged to the recency group 3 and customers that had made purchases during the past 12 months belonged to the recency group 2. Rest of the customers belonged to the recency group 1. The number of groups in each category is the same and can be company-specifically decided upon (typically 3 or 5). The number of customer segments is the number of groups to the power of three. For example, if the number of groups is three, as in FleetCo's case, then the number of customer segments is $3^{3}=27$.

The used segmentation model for FleetCo's industrial service customers improves the RFM model in three ways. First, it adds variables that describe a customer's installed base: fleet size fact (pcs) and potential ( $€$, estimation, based on installed base size). Second, it adds variables that describe a customer's spare part consumption. Part width is a fact about the number of different spare parts that the customer has purchased (count) during the review period. Part depth is a fact that tells the maximum amount (euros) spent on an individual spare part. Third, $\mathrm{P}($ alive $)$ is the model-estimated probability that a customer is still alive and it based on Pareto/Negative Binomial Distribution (Pareto/NBD distribution). Table 2 shows three example segments, their name and the interpretation made by the interventionist researcher who created the prediction model. As an example, "Stars" (RFM segment $3 \times 3 \times 3$ ) are customers that buy frequently and in high volumes. However, Part width, Part depth and Potential can still indicate possibilities to increase sales. Some stars might purchase part of their spare parts from competitors. In addition, exceptionally high Part width and Part depth compared to a customer's installed base might be an indication of equipment misuse. The company can use this information to advice customer and further increase customer satisfaction. 
Table 2. Example customer segments and their interpretation.

\begin{tabular}{lll}
\hline RFM Segment & Name & Interpretation \\
\hline $3 \times 3 \times 3$ & Stars & $\begin{array}{l}\text { Star customers buy frequently and in high volumes. Company must } \\
\text { keep these customers satisfied. In addition, Part width, Part depth and } \\
\text { potential indicate customers that can still increase their volume. Part } \\
\text { width and depth also potentially describe how customers use their } \\
\text { equipment or if customer purchases some spare parts from a competitor }\end{array}$ \\
$3 \times 2 \times 1$ & Potential & $\begin{array}{l}\text { Potential customers are active but they do not purchase in high volumes. } \\
\text { Depending on customer's installed base, potential customers provide an } \\
\text { opportunity to increase sales. }\end{array}$ \\
$1 \times 3 \times 3$ & Lost stars & $\begin{array}{l}\text { Lost stars purchased earlier frequently and in high volumes. However, } \\
\text { have not been active during the past year. P(alive) confirms if the } \\
\text { customer is lost for to competitor or any other reason. The company } \\
\text { should contact these customers immediately. }\end{array}$ \\
\hline
\end{tabular}

In FleetCo, the RFM analysis instantly inspired a new possibility. FleetCo could now see how the segments in the analysis relate to what kind of customer visits FleetCo's salespeople actually make. Possibly, this idea could reveal possibly misdirected service sales practice, which hold remarkable business implications given the limited resources in sales and marketing in different areas.

\section{Discussion and conclusions}

The paper describes the process of defining and structuring the technical possibilities stemming from the servitization (see e.g., Lindholm et al., 2017), and provides insights into discussions about the behavioural possibilities, that is building a shared understanding about servitization (Laine et al., 2012a; 2012b) and choosing most promising avenues for development efforts accordingly. Thus, the paper contributes to our understanding about the servitization of machinery manufacturers that requires both i) new sources of accounting information and ii) new forms of communication in utilizing it. Both these aspects jointly contribute to the identification and realizing the behavioural possibilities embedded in servitization, and to overcoming related difficulties.

Firstly, the paper contributes to the understanding about technical and behavioural possibilities in developing machinery fleet services. Based on the findings, the traditionally collected accounting facts are not sufficient for examining the business possibilities, but new information sources need to be utilized, and the attained information need to be constructed jointly and individually by the actors involved (Laine et al. 2016a, 2016b). Especially, in the fleet service context, new facts about the use of the machinery at the customer and thus related (technical) service business possibilities need to be thoroughly examined (Oliva \& Kallenberg, 2003, Laine et al. 2012a). Realizing such business possibilities requires, however, taking behavioural aspects into considerations, i.e., what is the desired division of tasks between the service provider and the customer in the future.

Secondly, the paper gives practical insight into how it is possible for machinery manufacturers to understand the factual possibilities the machinery fleet service market. From the perspective of pragmatic constructivism, the paper particularly highlights the role of individual managerial actors in identifying and putting forward the possibilities (requiring new information sources and new forms of communication among the actors). Many accounting facts could be gathered or constructed once actors found a proper form of collaboration and communication. In this case, a joint research program was the avenue to support FleetCo's otherwise limited resources with analytical skills offered by interventionist researchers. 
Thirdly, the paper addresses the lack of thorough knowledge about business impacts of accounting information systems in NPD. In FleetCo's service development case, information systems were utilized for gathering important accounting facts to understand, evaluate and predict market area or customer behaviour. Here, customers' service purchasing behaviour was a key aspect that could then be codified and statistically analysed. Moreover, FleetCo's own service sales behaviour could also be now questioned, once analyses opened new possibilities to focus service sales effors.

Finally, we see further research opportunities in further developing and reporting the effect of quantitative service analyses that will actually support service managers and service salespeople in their daily work. 


\section{References}

Adams-Bigelow, M. (2004). First Results from the 2003 Comparative Performance Assessment Study (CPAS). PDMA Handbook of New Product Development. K. B. Kahn. Hoboken, NJ, John Wiley and Sons: 546-566.

Ahrens, T., \& Chapman, C. S. 2004. Accounting for flexibility and efficiency: A field study of management control systems in a restaurant chain. Contemporary Accounting Research, 21(2): 271-301.

Anderson, A. M. 2008. A Framework for NPD Management: Doing the Right Things, Doing them Right, and Measuring the Results. Trends in Food Science and Technology, 19(11).

Araujo, L. and Spring, M. 2006. Services, products, and the institutional structure of production, Industrial Marketing Management, 35(7): 797-805.

Barczak, G. and Sultan, F. 2006. Use IT or Lose It. Marketing Management, 15(2): 30-34.

Barczak, G., Sultan, F. and Hultink, E. J. 2007. Determinants of IT Usage and New Product Performance. Journal of Product Innovation Management, 24: 600-613.

Beath, C. M. 1991. Supporting the Information Technology Champion. MIS Quarterly, 15(3): 355-372.

Cooper, R. G. and Edgett, S. J. 2008. Maximizing Productivity in Product Innovation. Research Technology Management, 51(2): 47-58.

Cooper, R. G. and Kleinschmidt, E. J. 1996. Winning Businesses in Product Development: the Critical Success Factors. Research Technology Management, 39: 18-29.

Davila, A., Foster, G., \& Oyon, D. 2009. Accounting and control, entrepreneurship and innovation: Venturing into new research opportunities. European Accounting Review, 18(2): 281-311.

Ettlie, J. E., Bridges, W. P. and O'Keefe, R. D. 1984. Organization Strategy and Structural Differences for Radical Versus Incremental Innovation. Management Science, 30(6): 682-695.

Gebauer, H., Fleisch, E., \& Friedli, T. 2005. Overcoming the service paradox in manufacturing companies. European Management Journal, 23(1): 14-26.

Grover, V. 1993. An Empirically Derived Model for the Adoption of Customer-Based interorganizational Systems. Decision Sciences, 24(3): 603-649.

Hall, M. 2010. Accounting information and managerial work. Accounting, Organizations and Society, 35(3), $301-315$.

Heinzelmann, R. 2016. Making up performance: the construction of "performance” in venture capital firms' portfolios. Qualitative Research in Accounting \& Management, 13(4): 445-471.

Jack, L. 2015. Further explorations of possibilities, methodologies of the future and rogue traders. Proceedings of Pragmatic Constructivism, 4(2): 32-38.

Jakobsen, M., Johansson, I.L. and Nørreklit, H. (Eds.). 2011, An Actor's Approach to Management: Conceptual Framework and Company Practices, DJØF Publishing, Copenhagen.

Jönsson, S., \& Lukka, K. 2006. There and back again: doing interventionist research in management accounting. Handbooks of Management Accounting Research, 1, 373-397.

Kawakami, T., Durmuşoğlu, S. S. and Barczak, G. 2011. Factors Influencing Information Technology Usage for New Product Development: The Case of Japanese Companies. Journal of Product Innovation Management, 28(6): 833-847.

Krishnan, V. and Ulrich, K. T. 2001. Product Development Decisions: A Review of Literature. Management Science, 47(1): 1-21.

Laine, T. 2009. Exploring pilot projects of a manufacturer on service $R \& D$ to understand service as an accounting object. Tampere University of Technology. Dissertation: publication 806.

Laine, T., Korhonen, T., \& Martinsuo, M. 2016a. Managing program impacts in new product development: An exploratory case study on overcoming uncertainties. International Journal of Project Management, 34(4), 717 733.

Laine, T., Korhonen, T., Suomala, P., \& Rantamaa, A. 2016b. Boundary subjects and boundary objects in accounting fact construction and communication. Qualitative Research in Accounting \& Management, 13(3), 303-329.

Laine, T., Paranko, J., Suomala, P. 2012a. Management accounting roles in supporting servitization: Implications for decision-making at multiple levels. Managing Service Quality, 22(3), 212-232.

Laine, T., Paranko, J., Suomala, P. 2012a. Using a business game concept to enhance servitization: a longitudinal case study. Managing Service Quality, 22(5), 428-446.

Liew, A. 2015. The Use of Technology-Structured Management Controls: Changes in Senior Management's DecisionMaking Behaviours. International Journal of Accounting Information Systems, 17: 37-64.

Lindholm, A., Laine, T. \& Suomala, P. Forthcoming. The potential of management accounting and control in global operations - profitability-driven service business development, Journal of Service Theory and Practice.

Lukka, K., \& Suomala, P. 2014. Relevant interventionist research: balancing three intellectual virtues. Accounting and Business Research, 44(2), 204-220. 
Mathieu, V. 2001. Service strategies within the manufacturing sector: benefits, costs and partnerships, International Journal of Service Industry Management, 12(5), 451-75.

Microsoft. 2005. Winning at New Products: Pathways to Profitable Innovation. White Paper, Microsoft Corporation and the Product Development Institute.

Neu, W.A. \& Brown, S.W. 2005. Forming successful business-to-business services in goods-dominant firms, Journal of Service Research, 8(1), 3-17.

Nørreklit, H., Nørreklit, L., \& Mitchell, F. 2010. Towards a paradigmatic foundation for accounting practice. Accounting, Auditing \& Accountability Journal, 23(6), 733-758.

Nørreklit, H., Raffnsøe-Møller, M., \& Mitchell, F. 2016. A pragmatic constructivist approach to accounting practice and research. Qualitative Research in Accounting \& Management, 13(3), 266-277.

Oliva, R. and Kallenberg, R. 2003, Managing the transition from products to services, International Journal of Service Industry Management, 14(2), 160-72.

Pianezzi, D., Cinquini, L., 2016. Assessing the validity of accounting for human rights: a pragmatic constructivist perspective. Qualitative Research in Accounting \& Management, 13(3), 370-391.

Sarin, S. 2009. Taking Stock and Looking Ahead: An Introduction to the Special Issue on New Product Development Teams. Journal of Product Innovation Management, 26(2): 117-122.

Stewart-Knox, B. and Michell, P. 2003. What Separates the Winners from the Losers in New Food Product Development? Trends in Food Science and Technology, 14 (1-2): 58-64.

Suomala, P., Lyly-Yrjänäinen, J., \& Lukka, K. 2014. Battlefield around interventions: A reflective analysis of conducting interventionist research in management accounting. Management Accounting Research, 25(4), 304314.

Teo, T. and Choo, W. (2001). Assessing the Impact of Using the Internet for Competitive Intelligence. Information and Management, 39(1): 67-83. 